\title{
Efficiency of Removal of Indoor Pollutants by Pistia stratiotes, Eichhornia crassipes and Hydrocotyle umbellata
}

\author{
Hye-Min Park ${ }^{1}$ and Ae-Kyung Lee ${ }^{2^{*}}$ \\ ${ }^{1}$ Master program in Environmental Horticulture, Dankook University, Cheonan 31116, Korea \\ ${ }^{2}$ Professor, Department of Environmental Horticulture, Dankook University, Cheonan 31116, Korea
}

\section{ABSTRACT}

In this study, we compared efficiency of different aquatic plants in removing indoor pollutants and examined their potential to purify indoor air. Two liter of water in chamber was used as the control, while the other chambers containing water lettuce (Pistia stratiotes), water hyacinth (Eichhornia crassipes), and water coin (Hydrocotyle umbellata) were used as treatment groups. Temperatures inside all the chambers were maintained between $20{ }^{\circ} \mathrm{C}$ and $23{ }^{\circ} \mathrm{C}$. Humidity in the chambers with aquatic plants increased by $30 \%$ and $50 \%$ control respectively. The removal of formaldehyde per unit leaf area was examined in each aquatic plant. It turned out that water hyacinth removed the highest amount of formaldehyde, followed by water lettuce and water coin. Both water hyacinth and water lettuce increased the amount of removal of formaldehyde until the end of the experiment. In the case of airborne dust (PM 10) and fine dust (PM 2.5), water coin, which had the highest number of leaves, removed more PM 10 and PM 2.5 than the other aquatic plants, with statistically significant difference. In addition, both water coin and water hyacinth smoothly opened and closed stomata before and after the experiment. Consequently, as the aquatic plants were effective in controlling humidity and removing pollutants, they can be used as air purifying plants.

Keywords: air purification, hydrophyte, particulate matter 2.5, particulate matter 10, phytoremediation

\section{Introduction}

As urbanization has been accelerated, the inflow of air into buildings has been minimized for the purpose of energy saving, and this has resulted in an increase in the concentration of pollutants in indoor environments. In addition, an increase in the time spent by those living in urban areas on indoor activities has raised their demand for a pleasant environment, which has tightened environmental standards for indoor pollutants (Ando, 2002). Dust is made of solid matter particles that are finer than sand, and depending on the size of particles, they are divided into airborne dust (PM 10), fine dust (PM 2.5) and ultrafine dust (PM 0.1; Ministry of Environment, 2017). Airborne dust (PM 10) is not filtered by the respiratory system. Since it infiltrates deep into the lungs and adheres to and damages the alveoli, a prolonged exposure to airborne dust affects an increase in the prevalence rate of asthma and pulmonary diseases and the premature death rate (Pope et al., 1992). Methods such as ventilation and air purifier are suggested as a way to remove fine dust in Korea, but it was reported that the pollution level of outdoor fine dust measured in Seoul was $60-80 \mu \mathrm{g} \cdot \mathrm{m}^{3}$ per day on average (Air Korea, 2018), which makes it difficult to ventilate air. When an air purifier is used, filters have to be frequently replaced and side effects such as bacterial reproduction are caused. Many studies have been conducted using eco-friendly plants to address such problems. Plants not only create a pleasant environment, but also give psychological stability. It was also reported that the distance between green space

Received: November 6, 2019, Revised: November 12, 2019, Accepted: January 10, 2020

First author: Hye-Min Park, dku_mini@naver.com, (10) https://orcid.org/0000-0002-5453-4214

*Corresponding author: Ae-Kyung Lee, akleekr@dankook.ac.kr, (1) https://orcid.org/0000-0003-2098-0360 
and indoor space affects the level of stress (van den Berg et al., 2010). In line with that, new terms such as green office and green healing have been introduced (Oh et al., 2019; Yoo et al., 2015) and the importance of the functions of plants started to be recognized. Apart from foliage plants, hydroponic elements that have audiovisual effects such as water and stone started to be introduced to decorate indoor spaces and people's interest in aquatic plants has ever grown (Lim et al., 2011). They are also widely used as an indoor landscaping material (Park et al., 2005). When aquatic plants are grown in pots, the time and labor spent on watering can be reduced, which allows even beginners to easily raise aquatic plants (Lee and Kim, 2003). In addition, the Indoor Air Quality Management Manual of Seoul (Seoul Metropolitan Government, 2014) suggests methods of installing pots and fishbowls as a way to naturally purify indoor air, and aquatic plants are expected to be increasingly utilized as a plant for purifying indoor air. Most of the earlier studies on air purification, however, targeted indoor foliage plants mostly, but aquatic plants have been researched only focusing on water quality such as waste water treatment and absorption of radioactivity.

Against this backdrop, this study was conducted to identify the effect of aquatic plants on the removal of indoor pollutants using water lettuce (Pistia stratiotes), water hyacinth (Eichhornia crassipes) and water coin (Hydrocotyle umbellata) and to examine their applicability as an air purifying plant.

\section{Research Methods}

\section{Testing materials}

The testing materials used in this study included water lettuce (Pistia stratiotes), water hyacinth (Eichhornia crassipes) and water coin (Hydrocotyle umbellata), and they were purchased from the Flower Market located in Yangjae-dong, Seoul in February, 2018. Their early characteristics were as shown in Table 1. A chamber filled with $2 \mathrm{~L}$ water only was used as the control group, and six pieces of each of Pistia stratiotes, Eichhornia crassipes and Hydrocotyle umbellata were placed in other chambers filled with $2 \mathrm{~L}$ of water and were used as a treatment group. In order to prevent pollutants from being generated during this experiment, glass water tanks (W $40 \mathrm{~cm} \times \mathrm{L} 25 \mathrm{~cm} \times$ $\mathrm{H} 28 \mathrm{~cm}$ ) were used as a chamber. The top of the chambers were covered with $2 \mathrm{~T}$ acrylic panels (W $42 \mathrm{~cm} \times \mathrm{L} 30 \mathrm{~cm}$ ), and Parafilm (Bemis, USA) was applied to seal the chamber to prevent any inflow of air. The pollutant used to treat the chambers was cigarette smoke according to the experiment method used in Han and Cha (2010). Cigarette smoke was generated for 5 minutes and was ensured to spread within the chambers using a rotating fan. The intensity of light in the chambers was maintained at $5.07 \pm 0.09 \mu \mathrm{mol} \cdot \mathrm{m}^{-2} \cdot \mathrm{s}^{-1}$ using a PPFD fluorescent light (Park et al., 2012), and the temperature and humidity in the chambers was maintained at $21.2 \pm 5.0{ }^{\circ} \mathrm{C}$ and $20.9 \pm 5.0 \%$ respectively. After completing each test, the surface of the chambers was disinfected using $80 \%$ ethanol to remove any residue of pollutants inside the chamber.

\section{Test items}

To measure the efficiency of aquatic plants in removing indoor pollutants, a data logger (WatchDog 1450, Spectrum Technologies, Inc., USA) was installed inside every chamber and changes in temperature and humidity were measured every 30 minutes. In addition, an indoor air quality detector (Sensology mef-550, LUKAI crop., China) was installed to measure the concentration of formaldehyde, PM 10 (Particulate Matter 10) and PM 2.5 (Particulate Matter

Table 1. Characteristic of the hydrophyte species used in the experiments

\begin{tabular}{lccccc}
\hline Hydrophyte & $\begin{array}{c}\text { Leaf length } \\
(\mathrm{cm})\end{array}$ & $\begin{array}{c}\text { Leaf diameter } \\
(\mathrm{cm})\end{array}$ & $\begin{array}{c}\text { Number of leaves } \\
(\mathrm{ea})\end{array}$ & $\begin{array}{c}\text { Plant weight } \\
(\mathrm{g})\end{array}$ & $\begin{array}{c}\text { Total leaf area } \\
\left(\mathrm{cm}^{2}\right)\end{array}$ \\
\hline P. stratiotes & 3.1 & 2.7 & 8 & 6.76 & 66.96 \\
E. crassipes & 2.4 & 4.1 & 7 & 14.93 & 68.88 \\
H. umbellate & 2.0 & 1.7 & 27 & 25.91 & 91.80 \\
\hline
\end{tabular}


2.5). Formaldehyde, PM 10 and PM 2.5 were measured every 30 minutes three times repeatedly, and changes in their concentration within chambers were measured for a total of 420 minutes. The removal efficiency of the control and treatment groups per unit leaf area and time was calculated (Kim and Yoo, 2011), and the leaf area applied to the control group was set as 0 . The stomata of aquatic plants were measured four times repeatedly using a stoma observation kit (SUMP, Kenis, Japan). An optical microscope (CX 31, Olympus, Japan) was used to measure the size of stomata, and after that they were photographed using a microscope camera (T500, eXcope, China) and Image $\mathrm{J}$, a computer program. The stomatal size of leaves was measured by calculating the rate of change in the size of light and shade before and after generating pollutants.

\section{Statistical analysis}

This experiment was repeated a total of 4 times. Data collected from the experiment were statistically analyzed using a statistical software (SAS 9.0, SAS institute Inc., Cary, USA) and Duncan's multiple range test at the significance level of $p \leq .05$.

\section{Results and Discussion}

Changes in the temperature inside chambers depending on the type of aquatic plants were measured (Fig. 1A), and the temperature inside all the treatment groups and the control group was $20-21{ }^{\circ} \mathrm{C}$ on average. The temperature in the chambers that contained aquatic plants started to gradually increase 180 minutes after the experiment began, and there were statistically significant differences between the control group and each of the treatment groups. In addition, the humidity (Fig. 1B) in the control group was $37.0 \pm 0.7 \%$ on average, and that in the treatment groups that contained aquatic plants (Pistia stratiotes, $68.9 \pm 16.1 \%$; Eichhornia crassipes, $70.9 \pm 15.1 \%$; and Hydrocotyle umbellata, $73.6 \pm 15.9 \%$ ) did not show significant differences between the treatment groups. However, compared to the control group, the humidity in the treatment groups sharply increased. The reason why the relative humidity in the treatment groups sharply increased seems to be that plants use about $1 \%$ of the water absorbed by their root in their body, and that the rest is emitted through their stomata and increases indoor humidity (Ju, 2010). The optimal indoor humidity suggested by the Ministry of Environment is $40-60 \%$, but the relative humidity in the treatment groups was measured to be $70 \%$ on average. Considering that this experiment was conducted inside chambers, when hydroponic elements are placed in actual indoor spaces, the humidity is expected to be controlled within the optimal range.

The removed amount of formaldehyde in the control and treatment groups was measured (Fig. 2). The removed amount in the control group $\left(0.0010 \mathrm{mg} \cdot \mathrm{m}^{-3} \cdot \mathrm{h}^{-1} \cdot \mathrm{m}^{-2}\right.$ leaf $)$ was relatively smaller than the treatment groups and there

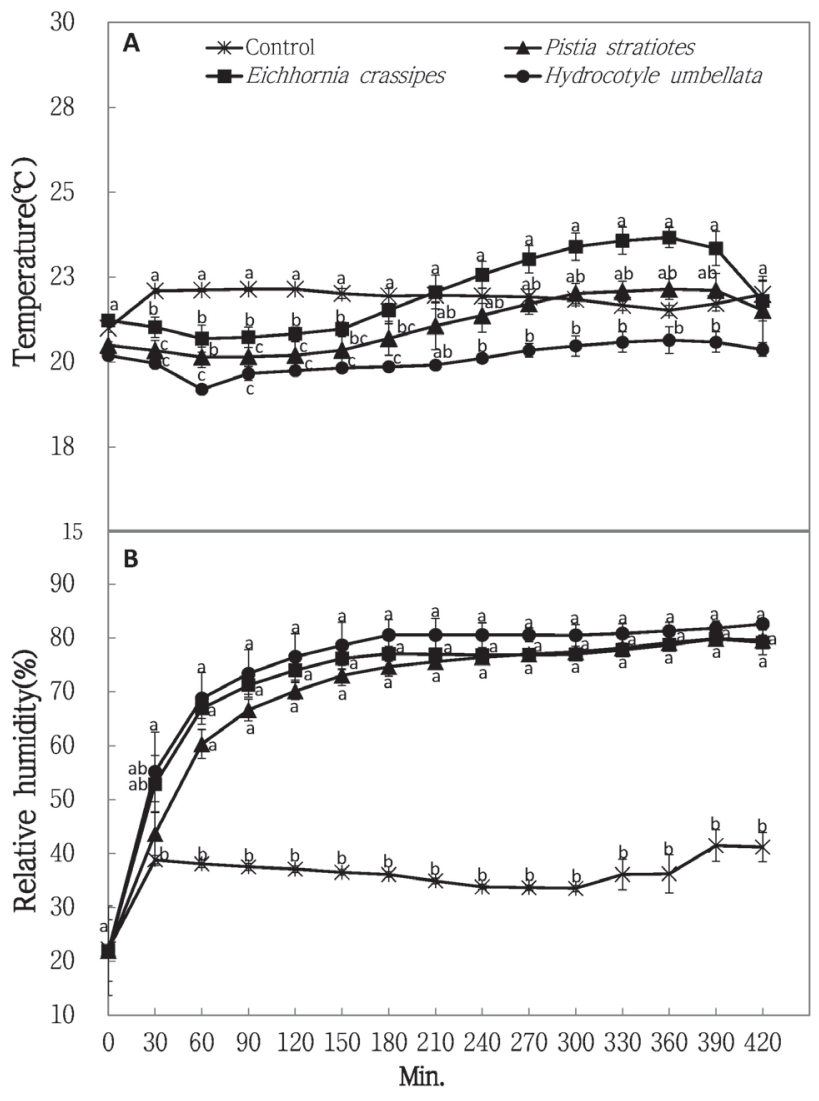

Fig. 1. Changes of temperature (A) and relative humidity (B) in the chambers of control group, Pistia stratiotes, Eichhornia crassipes and Hydrocotyle umbellata treatment groups for 420 minutes. Only $2 \mathrm{~L}$ of water was used in the chamber for control group. Values with different letters on the bar are significantly different by Duncan's multiple range test at $p \leq .05$. Vertical bars represent standard errors of the means $(n=4)$. 


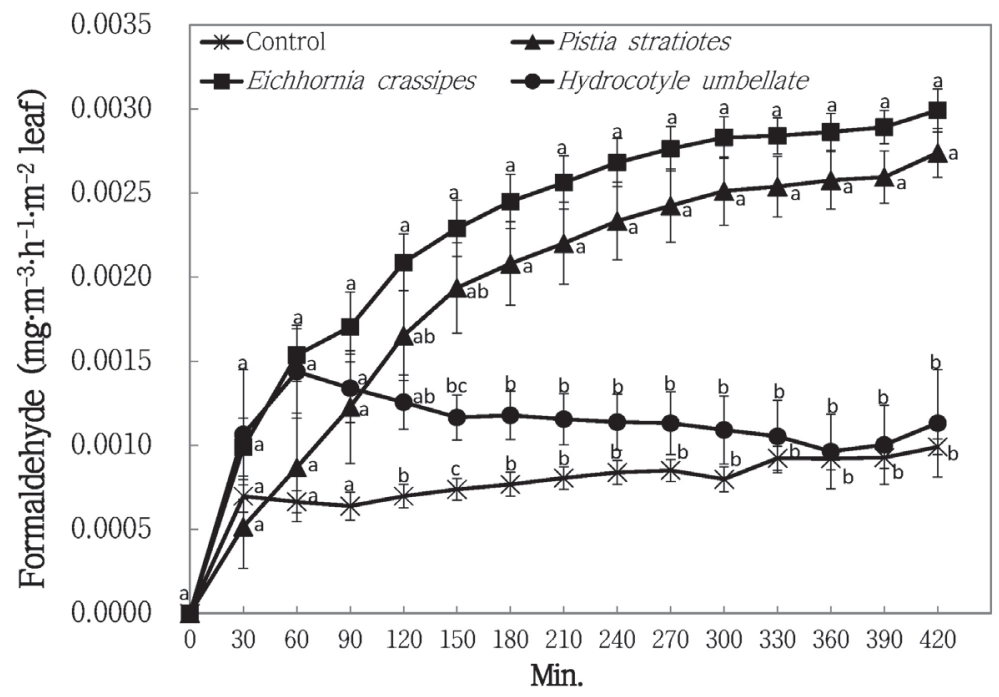

Fig. 2. The amount of formaldehyde removal in the control group, Pistia stratiotes, Eichhornia crassipes and Hydrocotyle umbellata treatment groups for 420 minutes in chamber. Values with different letters on the bar are significantly different by Duncan's multiple range test at $p \leq .05$. Vertical bars represent standard errors of the means $(n=4)$.

was no statistically significant difference between the control group and the treatment group of Hydrocotyle umbellata 180 minutes after the experiment began. However, the removed amount in the treatment groups of Pistia stratiotes and Eichhornia crassipes started to gradually increase right after this experiment began, and the total amount of formaldehyde removed by Eichhornia crassipes and Pistia stratiotes was $0.0030 \mathrm{mg} \cdot \mathrm{m}^{-3} \cdot \mathrm{h}^{-1} \cdot \mathrm{m}^{-2}$ leaf and $0.0027 \mathrm{mg} \cdot \mathrm{m}^{-3} \cdot \mathrm{h}^{-1} \cdot \mathrm{m}^{-2}$ leaf respectively, indicating that they were more effective in removing formaldehyde than the control group and the treatment group of Hydrocotyle umbellata. As the results of Choi (2008) showed, formaldehyde is dissolved in water when aquatic plants are placed in an indoor space.

The removed amount of PM 10 was measured (Fig. 3A), and that in the control group $\left(0.0575 \mathrm{mg} \cdot \mathrm{m}^{-3} \cdot \mathrm{h}^{-1} \cdot \mathrm{m}^{-2}\right.$ leaf) was lower than that in the treatment groups that contained aquatic plants, showing statistically significant differences. Differences between the treatment groups were compared, and the removed amount of PM 10 in all the treatment groups started to increase 210 minutes after the experiment began. The removed amount was measured after the experiment completed (420 minutes), and the amount removed by Hydrocotyle umbellata was the highest $\left(0.5434 \mathrm{mg} \cdot \mathrm{m}^{-3} \cdot \mathrm{h}^{-1} \cdot \mathrm{m}^{-2}\right.$ leaf), followed by Eichhornia crassipes $\left(0.4284 \mathrm{mg} \cdot \mathrm{m}^{-3} \cdot \mathrm{h}^{-1} \cdot \mathrm{m}^{-2}\right.$ leaf $)$ and Pistia strat-

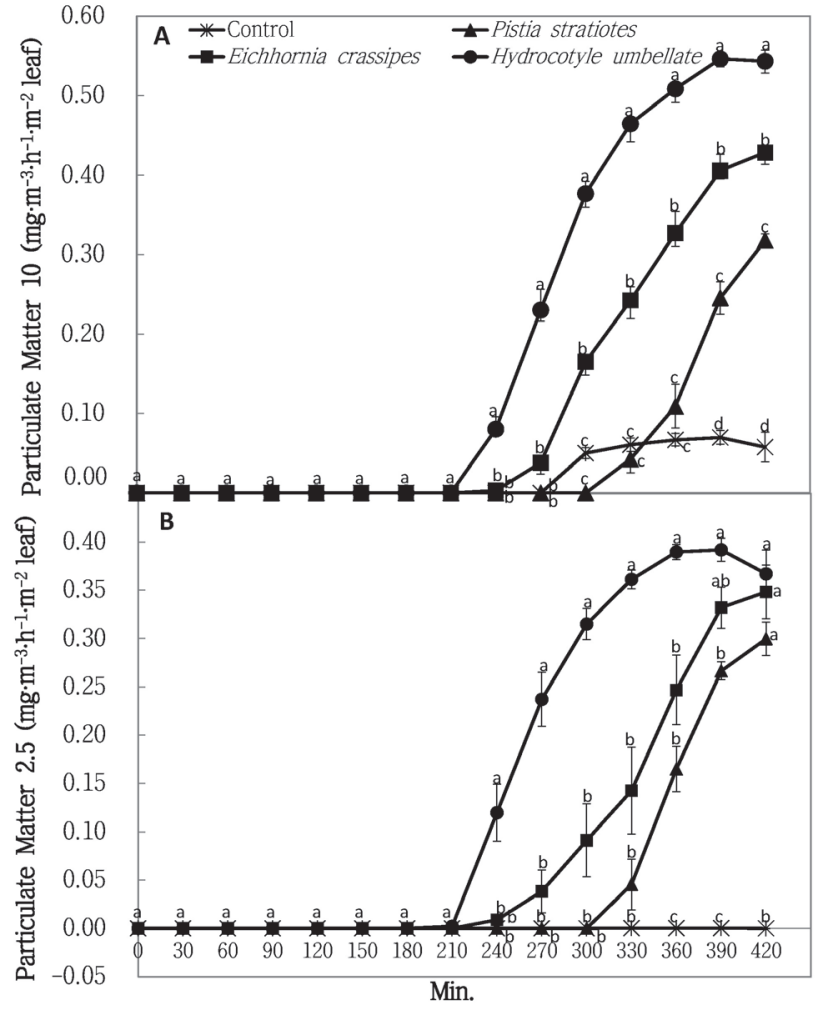

Fig. 3. The amount of Particulate Matter 10 (A) and Particulate Matter 2.5 (B) removal in the control group, Pistia stratiotes, Eichhornia crassipes and Hydrocotyle umbellata treatment groups for 420 minutes in chamber. Only $2 \mathrm{~L}$ of water was used in the chamber for control group. Values with different letters on the bar are significantly different by Duncan's multiple range test at $p \leq .05$. Vertical bars represent standard errors of the means $(n=4)$. 
iotes $\left(0.3179 \mathrm{mg} \cdot \mathrm{m}^{-3} \cdot \mathrm{h}^{-1} \cdot \mathrm{m}^{-2}\right.$ leaf $)$. These results were similar to those of Yoon et al. (2009) that all of the three indoor plants showed a higher PM 10 removal rate compared to the control group under the light and shade conditions. In addition, the removed amount of PM 2.5 in all the control and treatment groups (Fig. 3B) was identical to the results of PM 10. The removed amount of PM 2.5 in the control group was the lowest, showing statistically significant differences. Differences in the removed amount between the treatment groups, and Hydrocotyle umbellata showed statistically significant differences until 390 minutes passed, showing the highest removed amount. The amount of PM 2.5 removed by Pistia stratiotes and Eichhornia crassipes did not show statistically significant differences. These results were identical to the results of Kwon and Park (2017) that the more leaves plants within a chamber have, the shorter the time taken by plants to remove PM 10 and PM 1.0, and the higher their removal efficiency. Since the number of leaves of Hydrocotyle umbellata per piece was the highest in this study, the amount of PM 10 and PM 2.5 removed by the plant seemed to be the highest.

Changes in the stomatal size of plants were surveyed (Fig. 4). The change rate of the stomatal size of Pistia stratiotes before conducting the experiment was the only group that showed a statistically significant difference among other treatment groups, but after conducting the experiment the change rate was largely reduced. In addition, the change rate of the stomatal size of Eichhornia crassipes slightly declined after the experiment, while that of Hydrocotyle umbellata increased. However, there was no statistically significant difference in the rate of change after the experiment between the treatment groups. Stomata play an important role in the potential transpiration and photosynthesis of plants, prevent loss of moisture through the opening and closing of stomata and remove pollutants in the process of respiration through transpiration (Kim and Lee, 2017). The removed amount of formaldehyde per unit leaf area was also measured, and Eichhornia crassipes and Pistia stratiotes showed the highest removed amount, but the change rate of the stomatal size of Pistia stratiotes after the experiment was found to be reduced (Fig. 4), which highlights the necessity of additional experiments on the removal rate of plants when they are exposed to pollutants for a long period of time. In addition, Hydrocotyle umbellata was less effective in removing formaldehyde but it was found to be effective in absorbing and removing PM 10 and PM 2.5 and to well maintain the opening and closing of stomata. When using chambers, they are exposed to limited types of indoor pollutants only. In actual living spaces, however, even though pollutants are removed by plants, polluting gases are emitted again from construction

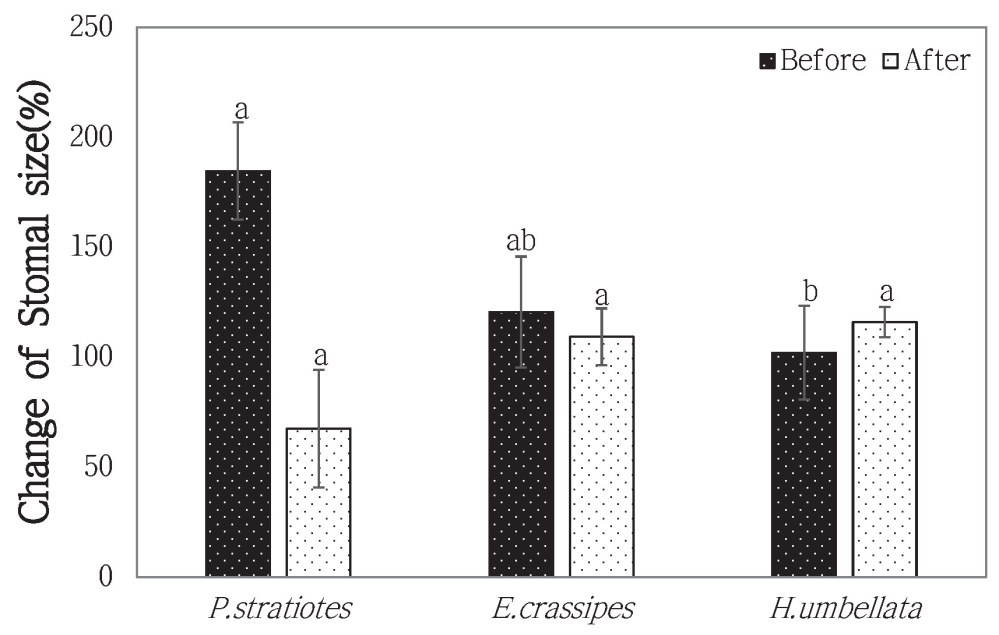

Hydrophyte species

Fig. 4. Changes of stomatal size (under light condition) of hydrophytes before and after the experiment. Vertical bars represent standard errors of the means $(n=4)$. 
materials, and thus speed is important in removing pollutants (Kim and Yoo, 2011). All the aquatic plants used in this study showed a similar removal point of time. The removed amount of formaldehyde differed depending on the leaf size of aquatic plants and was lower than the amount removed by a foliage plant, Chrysalidocarpus lutescens $\left(0.80 \mathrm{mg} \cdot \mathrm{m}^{-3} \cdot \mathrm{h}^{-1} \cdot \mathrm{m}^{-2}\right.$ leaf; Kim and Yoo, 2011), but was found to be effective in increasing humidity. In additoin, aquatic plants showed differences depending on their type and leaf area, but a significant amount of PM 10 and PM 2.5 was removed per leaf area for a unit time, showing that they were effective in removing pollutants.

\section{Conclusion}

This study was conducted to identify the effect of aquatic plants, Pistia stratiotes, Hydrocotyle umbellata and Eichhornia crassipes, on indoor air purifying. Changes in the temperature in a chamber depending on the type of aquatic plants were measured and there was no significant difference between the control and treatment groups. The humidity in the control group was about $22 \%$, and the humidity in the treatment groups was about $70 \%$ on average, although there were differences depending on the type of aquatic plants. Since aquatic plants grow in aquatic conditions, they are more effective in controlling indoor humidity than foliage plants. In addition, the removed amount of indoor pollutants was measured and the amount of formaldehyde removed by Eichhornia crassipes and Pistia stratiotes per leaf area was the highest. The removed amount of PM 10 and PM 2.5 was also measured, and Hydrocotyle umbellata showed a statistically significant difference and removed the highest amount per leaf area. Since formaldehyde is a soluble pollutant, aquatic conditions like a water tank in indoor spaces can remove formaldehyde. Increasing humidity makes particulate matters like PM 10 and PM 2.5 sink down, affecting the removal of indoor dust. The change rate of the stomatal size of plants was measured. The rate of Pistia stratiotes after conducting the experiment was reduced, while Hydrocotyle umbellata and Eichhornia crassipes did not show significant differences. Therefore, aquatic plants can be uti- lized well as its applicability as a plant for removing indoor pollutants is higher than in other places where aquatic conditions are prepared. However, since the leaf area of aquatic plants is small compared to foliage plants, a large amount of aquatic plants are required to be introduced to indoor spaces. In addition, pollutants can be removed not only by leaves but also by microorganisms that live in the soil where plants grow. For this reason, compared to foliage plants, their ability to purify air is relatively small. Therefore, it will be necessary to select effective aquatic plants compared to foliage plants.

\section{References}

Air Korea. 2018. Real-time air quality index PM 2.5. Retrieved September 9, 2019 from http://www.airkorea.or.kr/web/ pmRelay?itemCode $=11008 \&$ pMENU_NO=109

Ando, M. 2002. Indoor air and human health: Sick house syndrome and multiple chemical sensitivity. Kokuritsu Iyakuhin Shokuhin Eisei Kenkyūjo hōkoku [Bulletin of National Institute of Health Sciences]. 120:6-38.

Choi, J.R. 2008. Effects of air purification on indoor environment by dish gardens an pot plants. Doctoral dissertation, Chonbuk National University, Jeonju, Korea.

Han, H.S. and Y.L. Cha. 2010. Removal of the carbon monoxide in the indoor tobacco fume by the palm(two species). Proceedings of 2010 Spring Conference for Korean Society of Environment and Ecology (pp. 223-226). Seoul, Korea.

Ju, J.H. 2010. Change in the concentration of fine particles, temperature, and relative humidity as affected by different volume ratios of interior greening in real indoor space. J. Korean Environ. Restor. Technol. 13(2):1-7.

Kim, D.J. and J.S. Lee. 2017. Misconceptions and truths of morphological characteristics in plant stomata. J. Life Sci. 27(2):241-246. https://doi.org/10.5352/JLS.2017.2 7.2.241

Kim, K.J. and E.H. Yoo. 2011. Efficiency of formaldehyde removal according to the ground cover plants and materials of indoor potted plants. J. Korean Soc. People Plants Environ. 14(5):279-283.

Kwon, K.J. and B.J. Park. 2017. Effects of indoor greening 
method on temperature, relative humidity and particulate matter concentration. J. Korean Inst. Landsc. Archit. 5(4):1-10. https://doi.org/10.9715/KILA.2017.45.4.001

Lee, J.S. and S.N. Kim. 2003. Feasibility for horticultural use of Korean native water plants. J. Korean. Environ. Restor. Reveg. Technol. 6(1):41-50.

Lim, Y.H., W.J. Kim, W. Oh, and K.W. Kim. 2011. Analysis of currently-distributed species and ornamental uses of hydrophytes in korea. J. Korean Soc. People. Plants. Environ. 14(1):35-40.

Ministry of Environment. 2017. Find dust. Retrieved March 4, 2019 from http://me.go.kr

Oh, S.I., S.W. Cho, J.H. Lee, and A.K. Lee. 2019. Analysis of a survey on public perceptions and preferences of the "smart green office" to help encourage creation of the program. Flower Res. J. 27(1):60-67. https://doi.org/10.11623/frj.2019.27.1.09

Park, I.S., T.J. Lim, M.S. Lee, K.J. Cho, and W. Oh. 2012. Effects of various artificial light sources on growth and flowering in Begonia xhiemalis and Pelargonium crispum. J. Korean Soc. People Plants Environ. 15(6):465-470. https://doi.org/10.11628.ksppe.2012.15.6.465

Park, S.Y., J, Kim, Y.K. Jang, and K.J. Sung. 2005. A study on potential of aquatic plants to remove indoor air pollutants. J. Korean Environ. Restor. Reveg. Technol. $8(5): 1-9$.

Pope, C.A., III, J. Schwartz, and M.R. Ransom. 1992. Daily mortality and PM10 pollution in Utah valley. Arch. Environ. Health 47(3):211-217. https://doi.org/10.1080/0003989 6.1992 .9938351

Seoul Metropolitan Government. 2014. Indoor air quality management. Retrieved March 4, 2019 from http://clean indoor.seoul.go.kr

van den Berg, A.E., J. Mass, R.A. Verheij, and P.P. Groenewegen. 2010. Green space as a buffer between stressful life events and health. Soc. Sci. Med. 70(8):12031210. https://doi.org/10.1016/j.socscimed.2010.01.002

Yoo, E.H., H.S. Jang, K.J. Kim, H.H. Jung, and Y.J. Kim. 2015. Effect of green interior home on emotional psychology of human. J. Korean Soc. People Plants Environ. 18(4):249-256. https://doi.org/10.11628/ksppe.2015.18.4.249

Yoon, J.E., K.C. Son, D.S. Yang, and S.J. Kays. 2009. Removal of indoor tobacco smoke under light and dark conditions as affected by foliage plants. Korean J. Hortic. Sci. Technol. 27(2):312-318. 